\title{
Features of physiological status of aged people in sparsely circumpolar areas of Russia
}

\author{
Elena Yu. Golubeva, Raisa I. Danilova
}

Northern Arctic Federal University, Arkhangelsk, Russia; scorpic2005@mail.ru

Received 10 August 2012; revised 8 September 2012; accepted 17 September 2012

\begin{abstract}
Stable growth of the elderly age group is observed in the population of circumpolar areas of Russia. In northern conditions chronic pathology facilitates activity restriction development, changing the habitual lifestyle. Ageing process involves functional constraints of physical and mental activities, difficulties in doing everyday work. Aging changes of the nervous and respiratory systems are more characteristic of aged men and women living in the nursing home system of Russian urban circumpolar area. These changes are caused by worse psychological state, hypokinesia so there is a need in improveing approaches in medical and social care services, in particular, introducing activating technologies and the micro-environment enhancement.
\end{abstract}

Keywords: Sparsely Circumpolar Areas of Russian North; Elderly Population; Physiological Status

\section{INTRODUCTION}

In Russia over the last 60 years the proportion of children dropped almost by $50 \%$, whereas the proportion of elderly people increased by three times [1]. In his old age a person still has spare resources, development potential $[2,3]$, though the role of environment influence on ageing, social, hygienic, and psychophysiological factors gradually increases [4]. The elderly need medical treatment $50 \%$ more than middle-aged people.

Stable growth of the elderly age group is observed in the population of Euro Arctic region of Russia and the Arkhangelsk Region as well. Living conditions in the northern circumpolar regions are objectively characterized as unfavorable: lack of vitamins, abrupt photoperiodicity, high cyclonicity, abrupt changes in atmospheric pressure and temperature during the day, average low temperature per year. In addition, need in high-calorie food, in buying warm clothes and much more is another strain on a person which complicates age-specific adaptive changes.

The works of Russian and foreign researchers [5-7] state that physical and mental abilities of a body weaken gradually during ageing. It is quite impossible to point its exact beginning as it depends on individual body resources, on social conditions in which a person lives, as well as on a person's activity, food, lifestyle, etc. The study of ageing processes to define the age-specific changes intensity applies the approach to a human as a bio-psycho-social phenomenon due to various external and internal factors affecting the rate and symptoms both at the individual and population levels. The ageing process involves age-specific changes in organs and tissues along with changes caused by external influence. The ageing process is characterized by developing the adaptive mechanisms which slow vital bodily functions decline [8].

The aim of the study is to assess the physiological status of elderly people in urban (living in nursing house) and rural (living independently) areas in the Russian North with characterizing the affecting factors.

\section{METHODOLOGY}

The study of a lifestyle and micro-environment influence on the elderly functional systems involved a sample of 51 person aged $60-88$ (average age $(73.79 \pm 6.4)$ years), living in a nursing home in an urban area (18 men, 33 women); 50 people aged 62 - 87 (average age (72.27 \pm 6.4 ) years), living in a rural area (17 men, 33 women).

To find the dynamics of morphofunctional body changes with age the study of the urban and rural elderly examined:

- Body mass $(\mathrm{kg})$ with precision up to $0.5 \mathrm{~kg}$, body mass index was calculated $\left(\mathrm{kg} / \mathrm{m}^{2}\right)$;

- Standing height $(\mathrm{cm})$ with precision up to $0.5 \mathrm{~cm}$;

- Heart rate (HR) at the radial artery when muscles are in relative passive tone (bpm);

- Level of systolic (SP) and diastolic arterial pressure (DP) (mmHg). Pulsive pressure (PP) was calculated as SP-DP; 
- Vital lung capacity (1) with precision up to $100 \mathrm{ml}$ was calculated with a spirometer. Vital index was calculated (VI) $(\mathrm{ml} / \mathrm{kg})$;

- Stange's test (s);

- Romberg's test to examine coordination abilities (s);

- Test of attention and information processing speed (s).

The data statistical analysis was done with the SPSS 15.0 software, Excel 2000 software. Parametric and nonparametric methods were used: Student's t-criterionfor normal distribution, statistical significance of differences in independent samples was assessed with MannWhitney $U$ test. The descriptive statistics figures for variables with normal distribution are given as the arithmetic mean $(M)$ and standard error of the mean $( \pm \mathrm{m})$. The differences with statistical significance figure (p) below 0.05 were considered statistically significant.

\section{RESULTS AND DISCUSSION}

Elderly northerners tend to have multiple pathologies in their long-term chronic conditions. It leads to decreasing of functional systems figures, logically getting worse with age (38\% are observed to overestimate, $46 \%$ to underestimate somatic diseases). In northern conditions chronic pathology facilitates activity restriction development, changing the habitual lifestyle. Women's average height in rural areas is $152.4 \pm 4.87 \mathrm{~cm}$ with group-wide arm span of $142-162 \mathrm{~cm}$, body mass of $68.68 \pm 13.02 \mathrm{~kg}$, individual figures ranging from 45 to $100 \mathrm{~kg}$. Elderly women's height is lower than average, the number of people with obesity according to the body mass index (BMI) in the sample is $8.2 \%$.

Regarding the urban population, anthropometric data of people living in a nursing home are practically similar to the ones from the rural population. Women's average height was $151.05 \pm 30.2 \mathrm{~cm}$, the lower limit was $142 \mathrm{~cm}$, the upper limit was $162 \mathrm{~cm}$, the body mass was $65.2 \pm$ $15.9 \mathrm{~kg}$ with individual figures varying from 45 to 100 $\mathrm{kg}$. Elderly men's group revealed the average height of $161.8 \pm 9.3 \mathrm{~cm}$, with the minimum of $140 \mathrm{~cm}$ and the maximum of $174 \mathrm{~cm}$, the body mass was $68.0 \pm 12.79 \mathrm{~kg}$ with figures ranging from 53.5 to $95 \mathrm{~kg}$ (Table 1).

Men's height is $164.52 \pm 6.97 \mathrm{~cm}$, the lower limit is $157 \mathrm{~cm}$, the upper one is $186 \mathrm{~cm}$, body mass is $73.41 \pm$
$16.53 \mathrm{~kg}$ with variables from 48 to $108 \mathrm{~kg}$. Analysis of age-specific changes over a decade shows verifiable decreasing of body height by more than $3 \mathrm{~cm}$, caused by intervertebral discs flattening and an increased degree of stooping. This change corresponds to other studies' data on decreasing of a body height by $0.5-1 \mathrm{~cm}$ on average over five years after 60 [9]. The comparison of aged 60 69 years and 70 - 79 years groups shows the decline in body mass with age caused by its components changes which is a natural process. Changes are determined by loss of muscle mass and decrease in water content. Vertebral deformities lead to decreased chest mobility and respiratory muscle strength, as well as changes in bronchial patency and lung elasticity. Due to these changes VLC is decreased by more than $300 \mathrm{ml}$ in the female group, the general capacity becomes lower than the physiological norm [10]. A high level of respiratory disease in the Russian North conditions (ranked $2^{\text {nd }}$ place) [11], chronic bronchitis in particular, in the studied group, objectively proves the received data. The Russian scientists' works state that VLC of men aged $60-69$ is 1550 $\mathrm{ml}$ less than of men aged 20 - 29. Stange's test showed average figures in the age group, naturally decreasing a little due to functional age-specific changes.

The fact that the studied women and men in the rural area had more body mass than the ones living in a nursing home can also be mentioned. The decreasing of VLC of women and men living in a nursing home was verifiable. VLC of the elderly from the nursing home was below the norm which is related to the lifestyle, diseases, lack of activity there. The researchers state that the elderly patients' respiratory system functions not well enough with insufficient compensatory and adaptive mechanisms providing lung ventilation and gas exchange during intense activity $[12,13]$. A very important role is played by intense physical activity in the open air which can stimulate functions and improve the respiratory system adaptive abilities.

Most respondents, taking part in the research, complained of regular headaches, 25\% mentioned hypertension. The study of arterial pressure (AP) showed the following results (Table 2 ).

The assessment of elderly patients' cardiovascular system showed that the studied parameters are within the

Table 1. Comparative analyzes of physiological indicators of elderly people in urban and rural circumpolar areas of Russia, $\mathrm{M} \pm \mathrm{m}$, $\mathrm{N}=101$.

\begin{tabular}{|c|c|c|c|c|}
\hline Area/sex & Body mass index (BMI) $\left(\mathrm{kg} / \mathrm{m}^{2}\right)$ & Vital index $(\mathrm{ml} / \mathrm{kg})$ & Vital lung capacity (1) & Stange's test (s) \\
\hline Rural indep./female $(n=33)$ & $29.4 \pm 5.19$ & $28.78 \pm 8.23^{*}$ & $1909.1 \pm 448.81^{*}$ & $22.0 \pm 8.64$ \\
\hline Urban nurs. house/female $(\mathrm{n}=33)$ & $28.6 \pm 5.7$ & $19.6 \pm 7.8$ & $1277.1 \pm 570.70$ & $20.4 \pm 12.30$ \\
\hline Urban nurs. house/male $(\mathrm{n}=18)$ & $26.2 \pm 10.9$ & $23.1 \pm 6.19$ & $1568.4 \pm 696.90$ & $22.7 \pm 11.46$ \\
\hline
\end{tabular}

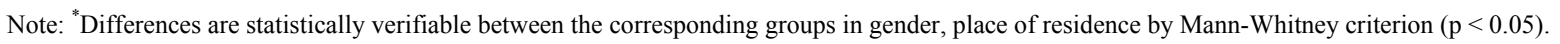


Table 2. Comparative analyzes of arterial pressure indicators of elderly people in urban and rural circumpolar areas of Russia, $\mathrm{M}$ $\pm \mathrm{m}, \mathrm{N}=101$.

\begin{tabular}{ccccc}
\hline Index $(\mathrm{mmHg})$ & Urban nurs. house/male $(\mathrm{n}=18)$ & Rural indep./male $(\mathrm{n}=17)$ & Urban nurs. house/female $(\mathrm{n}=33)$ & Rural indep./female $(\mathrm{n}=33)$ \\
\hline Sistolic AP & $141.8 \pm 23.39$ & $159.7 \pm 29.21$ & $143.2 \pm 34.80$ & $161.4 \pm 30.76^{*}$ \\
Diastolic AP & $83.2 \pm 10.38$ & $86.1 \pm 15.80$ & $81.4 \pm 18.02$ & $93.5 \pm 21.29^{*}$ \\
Pulsive AP & $58.4 \pm 19.05$ & $73.6 \pm 24.48$ & $61.8 \pm 20.86$ & $67.9 \pm 26.37$ \\
\hline
\end{tabular}

Note: ${ }^{2}$ Differences are statistically verifiable between the corresponding groups in gender, place of residence by Student's criterion ( $\mathrm{p}<0.01$ ).

physiological norm and the SAP of the studied group fluctuates from 110 to $160 \mathrm{mmHg}$. The data from other sources show that normal AP is stable at the age of 20 59 , then rises a little at the age of $60-69$, and shows a significant rise after 70 years (SAP 145 - $153 \mathrm{mmHg}$ ). However, there are regional variations of elderly people arterial pressure [14]. High AP of the group aged $60-69$ objectively corresponds to $25 \%$ diagnosed with hypertension. In addition, insufficient medical care for people in a rural area, lack of specialists and low income prevents the elderly from buying qualitative medicines for the treatment.

With age VLC and VI are observed to decrease. Most radical changes were registered in the group of men and women in the nursing home which is a result of the lifestyle, diseases and lack of activity during free time there. The patients' medical records reveal bronchial asthma in $10 \%$ of cases, chronic bronchitis-32\%. Cardiovascular system functional state of elderly people from the rural area is characterized by increasing systolic AP and diastolic AP, increased pulse pressure more typical for women. Besides, insufficient medical care for people in a rural area, lack of specialists and low income prevents the elderly from buying qualitative medicines for the treatment. Lower AP closer to the physiological norm characterizes men and women living in the nursing home compared with the ones living in the rural area $(\mathrm{p}<0.01)$, which is probably connected with the organization staff care, timely medication administration. The place of residence and getting the necessary care influence the cardio-respiratory system functional indicators.

The nervous system ageing is a key factor in the whole body ageing. It is reflected in morpho-functional and psycho-physiological changes affecting mental and physical performance, memory and other life aspects. Muscle strength, reaction speed, visual and hearing acuity, agility, endurance and other psycho-physiological qualities naturally deteriorate with age.

Absolutely every participant of the research coped with the attention and information processing speed test. It took women 45 to 225 seconds with the average result of $103.27 \pm 52.63$ seconds, men-60 to 183 seconds with the average result of $118.11 \pm 44.01 \mathrm{sec}$. The urban people spent the following time on doing a similar test with consecutive crossing out of numbers: women-156.6 \pm
$67.6 \mathrm{sec}$ and men- $-175.8 \pm 85.1 \mathrm{sec}$, which is 1.5 times more than the residents of rural areas. Age-related changes of vision are characterized by farsightedness in most cases and a high per cent of visually impaired among the elderly.

The assessment of information processing speed showed the following tendencies: women and men from the rural area coped with the given test faster than the ones from the nursing home $(\mathrm{p}<0.05)$. The considerable variability in data is explained by irregular course of ageing among the group, in particular, facilitation of involutional changes in concentration and attention allocation of the people from the nursing home.

Same researches state the elderly suffer to a great extent from injuries resulting from falls, $40 \%-60 \%$ of which lead to fractures $[15,16]$. I. Vikman et al., 2011 [17] note that many aged people have problems with balance which causes injuries, especially in circumpolar conditions where falls with injuries peak in winter.

When doing Romberg's test elderly women found it hard to keep balance. $40 \%$ of the studied from the nursing home could not do the test due to functional disorders compared with $15.1 \%$ of the ones from the rural area. $51.5 \%$ of rural women had results lower than 10 seconds, whereas $15.1 \%$ did the test with more than 50 seconds' result which is higher than the physiological norm. 92\% of women from the nursing home kept balance less than 10 seconds, $8 \%$ more than 20 seconds. Romberg's test results are shown in Figure 1.

$50 \%$ of the studied men from a large nursing home failed the test, $90 \%$ of cases had results lower than 10 seconds with the mean number being $10.08 \pm 1.7 \mathrm{~s}$. $17.6 \%$ of rural men could keep balance for more than a minute which is higher than the physiological norm. Comparing the samples different in residence showed that men and women from the nursing home have verifiably worse results of coordination abilities when performing Romberg's test $(\mathrm{p}<0.01)$. The tendency for coordination abilities to decline from a younger age group to an older age group was noted corresponding to the data from M.A. Savenko (2009) [18]. Decline in nervous processes liability, coordination abilities and the respiratory system is more characteristic of the elderly that stay in the nursing home in the urban area with hypokinesia. Leading independent life in the rural area, 


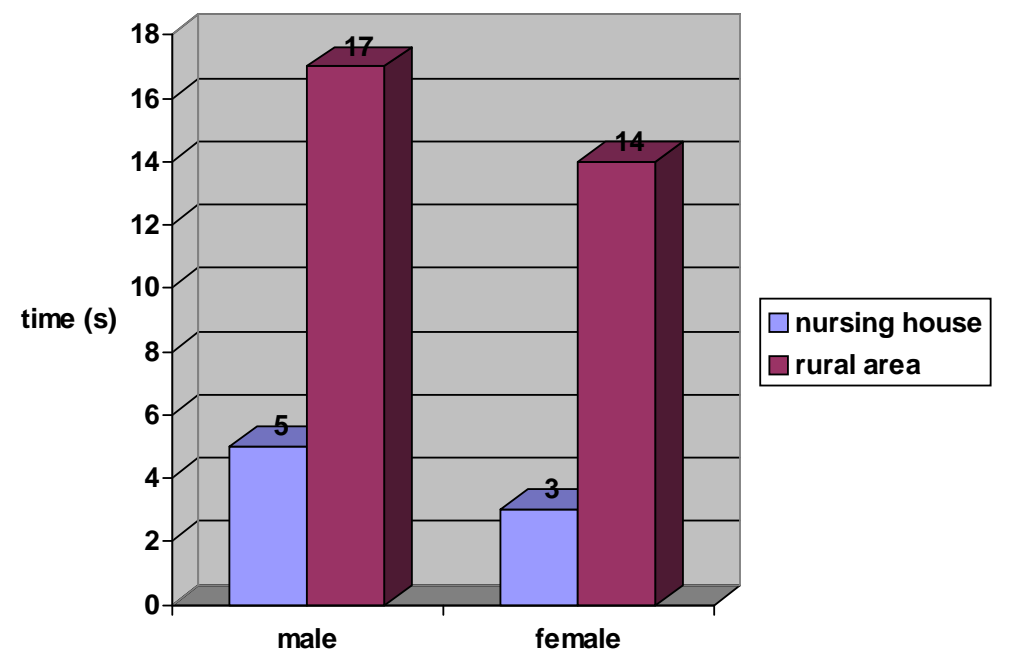

Figure 1. Indexes of Romberg's test of elderly population in rural and urban circumpolar areas.

spending free time in an active way, keeping fit in everyday life enable better condition of the corresponding systems functions of the aged men and women.

\section{CONCLUSIONS}

Changes due to age are the physiological processes which according to Agadzhanyan N. (2010) [19] are not a disease, primarily, though lead to limited functional abilities of the organism and decreased resistance to harmful effects. Ageing process involves functional constraints of physical and mental activities, difficulties in doing everyday work.

Mantly et al. (2009) [20] point at a positive effect produced by physical activity on daily operations constraints, on decreasing life constraints, which can be connected with relatively high VLC, Stange's test of the elderly living in the circumpolar rural area. Aging changes of the nervous and respiratory systems are more characteristic of aged men and women living in the nursing home system of Russian circumpolar area. These changes are caused by worse psychological state, hypokinesia so there is a need in improving approaches in medical and social care services, in particular, introduceing activating technologies and the micro-environment enhancement.

\section{REFERENCES}

[1] Safarova, G. (2009) Demography of aging: Modern status and priority directions of research. Advances in Gerontology, 22, 49-59.

[2] Savenko, M.A. (2009) Determinants of active longevity of elderly people. Ph.D. Thesis, Institute of Bioregulation and Gerontology, St. Petersburg.

[3] Wilcox, S., Dowda M., Griffin, S.F., et al. (2006) Results of the first year of active for life: Translation of 2 evidence-based physical activity programs for older adults into community settings. American Journal of Public Health, 96, 1201-1209. doi:10.2105/AJPH.2005.074690

[4] Shraga, M. (2009) Social safety in health theory. Kira, Arkhangelsk.

[5] Savenko, M.A. (2009) Determinants of active longevity of elderly people. Ph.D. Thesis, Institute of Bioregulation and Gerontology, St. Petersburg.

[6] Borsch-Supan, A., Hank, K., Jurges, H. And Schroder, M. (2009) Introduction: Empirical research on health, aging and retirement in Europe. Journal of European Social Policy, 19, 293-300. doi:10.1177/1350506809341510

[7] Goldsmith, T.C. (2009) Biological aging and implications for public health: Executive summary. Azinet Press, 5964.

[8] Agadzhanyan, N. (2010) Human physiology. Akadempress, Moscow.

[9] Khisanfova, E. (1999) The basics of gerontology (anthropological aspects). Vlados, Moscow.

[10] Varlamova, N. and Evdokimov, V. (2006) The function of external inspiration of women in different ages. Advances in Gerontology, 19, 85-89.

[11] Shraga M. (2009) Social safety in health theory. Kira, Arkhangelsk.

[12] Varlamova, N. and Evdokimov, V. (2006) The function of external inspiration of women in different ages. Advances in Gerontology, 19, 85-89.

[13] Prokopenko N. (2007) The role of social and hygienic factors and psychophysiological features of personality in aging. Advances in Gerontology, 21, 153-159.

[14] Agadzhanyan, N. (2010) Human physiology. Akadempress, Moscow.

[15] Lord, S., Sherrington, C., Menz, H., et al. (2007) Falls in older people. Rick factors and strategies for prevention. 2nd Edition, Cambridge University Press, Cambridge. doi:10.1017/CBO9780511722233 
[16] Freiberger, E. and Menz, H.B. (2006) Characteristics of falls in physically active community-dwelling older people. Zeitschrift für Gerontologie und Geriatrie, 39, 261267. doi:10.1007/s00391-006-0394-2

[17] Vikman, I., Nordlund, A., Naslund, A., et al. (2011) Incidence and seasonality of falls amongst old people receiving home help services in a municipality in northern Sweden. International Journal of Circumpolar Health, 70, 195-204. doi:10.3402/ijch.v70i2.17813

[18] Savenko, M.A. (2009) Determinants of active longevity of elderly people. Ph.D. Thesis, Institute of Bioregulation and Gerontology, St. Petersburg.

[19] Agadzhanyan N. (2010) Human physiology. Akadempress, Moscow.

[20] Mänty, M., Heinonen, A., Leinonen, R., et al. (2009) Long-term effect of physical activity counseling on the development of mobility limitation among older people: A randomized controlled study. Journal of Gerontology: Medical Sciences, 64, 83-89. 